\title{
PENDAMPINGAN LANSIA DALAM PENCEGAHAN KOMPLIKASI HIPERTENSI
}

\author{
Emdat Surayitno ${ }^{1)}$, Naily Huzaimah²) \\ 1) Program Studi Profesi Ners, Fakultas IImu Kesehatan, Universitas Wiraraja, Sumenep, Jawa Timur, Indonesia \\ 2) Program Studi Keperawatan, Fakultas IImu Kesehatan, Universitas Wiraraja, Sumenep, Jawa Timur, Indonesia
}

Corresponding author : Emdat Suprayitno

E-mail : emdat@wiraraja.ac.id

Diterima 24 September 2020, Direvisi 08 Oktobet 2020, Disetujui 10 Oktober 2020

\begin{abstract}
ABSTRAK
Hipertensi adalah penyakit kronis yang umum di seluruh dunia dan faktor risiko utama penyakit kardiovaskular. Penyebab utama penyakit ini yaitu faktor genetika, perilaku dan gaya hidup. Kesadaran yang rendah pada penanganan hipertensi menjadi penyebab utama dalam terjadinya komplikasi stroke. Desa Karanganyar Barat Kecamatan Kalianget Kabupaten Sumenep Merupakan salah satu desa yang terletak di daerah pesisir dan juga banyak terdapat tambak garam. Data posyandu lansia Desa Karanganyar Barat menyebutkan bahwa angka kejadian hipertensi pada lansia sangat tinggi bahkan kunjungan posyandu terbanyak adalah penderita hipertensi mencapai $70 \%$. Para lansia ini juga kurang memahami dampak jangka Panjang hipertensi seperti stroke. Tujuan dalam pengabdian untuk meningkatkan pengetahuan lansia dalam mencegah komplikasi hipertensi. Mitra dalam pengabdian ini adalah kader posyandu lansia di Desa Karanganyar Barat Kecamatan Kalianget Kabupaten Sumenep, Peserta dalam kegiatan ini adalah lansia penderita hipertensi sebanyak 15 orang. Metode dalam kegiatan ini yaitu penyuluhan, ceramah dan diskusi. Keberhasilan acara ini tampak dari semangat dan antusiasnya lansia. Lansia juga berperan sangat aktif dalam menjawab evaluasi tentang materi yang telah disampaikan. Pelaksanaan kegiatan pengabdian terlaksana dengan lancar, Sebagian besar $93 \%$ (14 lansia) meningkat pengetahuannya dengan kategori pengetahuan baik sedangkan 6,7\% (1 orang) dengan kategori pengetahuan cukup dalam mencegah komplikasi hipertensi serta berkomitmen dalam melaksanakan semua anjuran dari tim pengabdian untuk mencegah komplikasi stroke.
\end{abstract}

Kata kunci: lansia; hipertensi; komplikasi hipertensi.

\begin{abstract}
Hypertension is a common chronic disease worldwide and a major risk factor for cardiovascular disease. The main causes of this disease are genetics, behavior, and lifestyle. Low awareness of hypertension management is the main cause of stroke complications. Karanganyar Barat Village, Kalianget District, Sumenep Regency is one of the villages located in a coastal area and there are also many salt ponds. Data from the Posyandu for elderly in Karanganyar Barat Village states that the incidence of hypertension in the elderly is very high, even if the most posyandu visits are hypertension sufferers reaching $70 \%$. The elderly also do not understand the long-term impact of hypertension such as stroke. This research aims to increase the knowledge of the elderly in preventing complications of hypertension. Partners in this service are elderly posyandu cadres in Karanganyar Barat Village, Kalianget District, Sumenep Regency. Participants in this activity were 15 elderly people with hypertension. The methods in this activity are counseling, lectures, and discussions. The success of this event was evident from the enthusiasm and enthusiasm of the elderly. The elderly also play a very active role in answering evaluations of the material that has been delivered. The implementation of service activities was carried out smoothly, most of the $93 \%$ (14 elderly) increased their knowledge with the good knowledge category, while $6.7 \%$ (1 person) with the category of knowledge was sufficient in preventing complications of hypertension and committed to carrying out all recommendations from the service team to prevent complications stroke.
\end{abstract}

Keywords: elderly; hypertension; complications of hypertension.

\section{PENDAHULUAN}

Hipertensi merupakan faktor risiko penting untuk penyakit neurologis. Hipertensi kronis merupakan faktor risiko utama untuk semua subtipe stroke, termasuk stroke iskemik, perdarahan intraserebral, dan perdarahan subarachnoid. hipertensi telah menjadi faktor risiko utama utama untuk penyakit kronis dan kematian. WHO merekomendasikan pentingnya 
pelayanan kesehatan primer dalam memerangi hipertensi dan tenaga kesehatan, terutama perawat, harus berperaan dalam menciptakan kesadaran di antara anggota masyarakat dan mereka harus berperan aktif dalam menyelenggarakan pendidikan Kesehatan tentang faktor risiko (Kilic et al., 2016). kejadian hipertensi akan bertambah dengan bertambahnya umur seseorang. Pada usia 25 sampai 44 tahun kejadian hipertensi mencapai $29 \%$, pada usia 45 sampai 64 tahun mencapai $51 \%$, dan pada usia lebih 65 tahun mencapai $65 \%$. (Warjiman et al., 2020). Meningkatnya kejadian penyakit darah tinggi mengakibatkan jumlah kematian serta terjadinya resiko komplikasi akan semakin bertambah setiap tahunnya. Penyebab keadaan ini karena hipertensi angka kejadiannya masih sangat tinggi di wilayah yang berpenghasilan rendah dan terjadi pada usia lanjut. diperlukan solusi terbaik untuk mengatasi hipertensi. solusi diharapkan dapat menurunkan angka kejadian hipertensi, menurunkan resiko terjadinya komplikasi, dan mengurangi resiko terhadap penyakit bagian kardiovaskuler (E Suprayitno \& Wahid, 2019)

Di Asia Tenggara hampir 1,5 juta jiwa meninggal disebabkan oleh menderita hipertensi tiap tahun, kondisi ini menjadikan darah tinggi menjadi faktor tertinggi penyebab kematian. Peningkatan jumlah orang dewasa di Indonesia dengan hipertensi mencapai $8 \%$ pada tahun 1995 dan meningkat mencapai 32\% tahun 2008 (WHO, 2013). Riset Kesehatan Dasar 2013 menyebutkan kejadian hipertensi di Indonesia melalui pada renatng usia $\geq 18$ tahun terbanyak terdapat pada Bangka Belitung (30,9\%), kemudian Kalimantan Selatan (30,8\%), Kalimantan Timur (29,6\%) dan Jawa Barat $(29,4 \%)$. Sebagian besar lansia di Desa Karanganyar berada pada Klasifikasi Hipertensi Derajat I (tekanan darah 140-159 $\mathrm{mmHg}$ ) dengan rata-rata usia 56-60 tahun (Suprayitno, 2019). Kemenkes RI (2014) menyatakan bahwa mencegah dan mengatasi masalah hipertensi di Indonesia harus dimulai dengan menambah tingkat kesadaran masyarakat dalam membuat perubahan kebiasaan hidup yang lebih sehat. Demi mewujudkan hal tersebut, maka perlu dilakukan kegiatan pengabdian masyarakat dalam bentuk Skrinning dan Penyuluhan tentang Hipertensi (Warjiman et al., 2020)

Penderita hipertensi mayoritas mempunyai keluhan bergantung pada anda dan gejala yang dirasakan pada saat itu tanpa peduli terhadap penanganan yang lebih intensif dan tepat. Kondisi ini dapat diakibatkan karena kurangnya pengetahuan masyarakat pada penyakit hipertensi serta penanganan yang baik dan tepat secara rutin (Alfian, 2015). Rekomendasi dalam mengatasi hipertensi sebisa mungkin diaaalksanakan dengan maksimal oleh penderita hipertensi dan tim kesehatan melalui tindakan farmakologis dan non farmakologis untuk menurunkan tekanan darah. Rekomendasi untuk self management hipertensi menurut The European Society of Hypertension meliputi modifikasi gaya hidup dan terapi pengobatan. penatalaksanaan non farmakologis dalam mengurangi kejadian hipertensi dapat dilaksanakan dengan memodifikasi gaya hidup. Ragot et. al., (2005) berpendapat jikabahwa penderita hipertensi yang memodifikasi gaya hidup dalam mengontrol tekanan darahnya terdapat hanya sebanyak $30 \%$ dari seluruh penderita hipertensi. Seseorang yang menderita penyakit kardiovaskuler diharapkan untuk melakukan perawatan terhadap dirinya sendiri sebagai salah satu penanganan penyakit untuk menongkatkan kulaitas hidup (Richard \& Shea, 2011).

$$
\text { Modifikasi gaya hidup juga }
$$
mengharuskan pasien untuk dapat membaca label makanan dan memilih makanan sehat. Literasi kesehatan adalah kemampuan membaca, menulis, dan memahami informasi yang berkaitan dengan kesehatan - dalam hal ini khususnya informasi yang berkaitan dengan manajemen dan pengendalian hipertensi. (Mafutha et al., 2017). Rekomendasi manajemen hipertensi menurut Canadian Hypertension Education Program (2014) yaitu: modifikasi perilaku hidup sehat, kurangi berat badan, kurangi konsumsi alkohol, manajemen diet, pembatasan sodium, diet kalsium dan magnesium, dan menghindari stress (Widimský, 2016), (Taghadosi, 2017). Manajemen diri hipertensi diharapkan untuk meningkatkan pengetahuan lansia tpada penyakit hipertensi, memperbaiki sikap dan kepatuhan pengobatan penyakitnya. Semuanya bisa diterapkan dengan cara pemberian edukasi pada penderita hipertensi yang bertujuan mengurangi tekanan darah dan faktor-faktor resiko terjadinya hipertensi. (Fernalia et al., 2019). Agar lansia penderita hipertensi peduli kesehatan tentang hipertensi, tenaga kesehatan perlu membekali mereka dengan penyuluhan kesehatan hipertensi dan menjelaskan tentang hipertensi, penatalaksanaan dan prognosisnya Suprayitno et al., 2020). Setelah itu, pasien memiliki tanggung jawab untuk memahami dan mengikuti rejimen penatalaksanaan hipertensi sesuai dengan resep mereka untuk manajemen sukses dan pengendalian hipertensi.(Nutbeam, 2000). Tujuan Kegiatan pengabdian ini adalah untuk meningkatkan pengetahuan lansia penderita hipertensi untuk mencegah komplikasi stroke. 


\section{METODE}

Pengabdian masyarakat ini dilaksanakan pada hari Kamis, 14 September 2020, di Rumah Kader Posyandu lansia Desa Karanganyar Kecamatan Kalianget kabupaten Sumenep. Mitra dalam kegiatan ini adalah kader posyandu lansia di Desa Karanganyar Barat Kecamatan Kalianget Kabupaten Sumenep. Peserta pengabdian yaitu 15 orang lansia penderita hipertensi. Metode yang digunakan dalam pengabdian masyarakat ini adalah pengisian kuesioner pengetahuan peserta tentang penyakit hipertensi dan pencegahan komplikasi stroke. Kemudian melakukan pemeriksaan tekanan darah yang dibantu oleh mahasiswa program studi keperawatan. Penyuluhan dan ceramah dilakukan melalui penyampaian materi terkait pengertian, factor penyebab, tanda gejala dan pencegahan komplikasi hipertensi. Narasumber berasal dari dosen pengajar mata kuliah keperawatan gawat darurat Fakultas IImu Kesehatan Universitas Wiraraja. Kegiatan yang terakhir adalah diskusi dan tanya jawab tentang penyakit hipertensi dilakukan setelah penyuluhan, kemudian dilakukan pengisian kuesioner pengetahuan tentang penyakit hipertensi dan pencegahan komplikasi stroke.

\section{HASIL DAN PEMBAHASAN}

Kegiatan pengabdian pendampingan lansia dalam mencegah komplikasi hipertensi dilaksanakan di rumah kader posyandu lansia Desa karangayar barat Kecamatan kalianget Kabupaten Sumenep. Pelaksanaan pendampingan pencegahan komplikasi hipertensi pada lansia terlaksana tanpa hambatan dan lancar. Kegiatan ini dilaksanakan selama 3 kali selama sebulan. Pendampingan ini dibagi menjadi tiga tahapan sebagai berikut : 1. Pemeriksaan tekanan darah

Tahapan yang pertama adalah pemeriksaan tekanan darah yang dibantu oleh mahasiswa program studi keperawatan fakultas ilmu Kesehatan Universitas Wiraraja (Gambar 1)

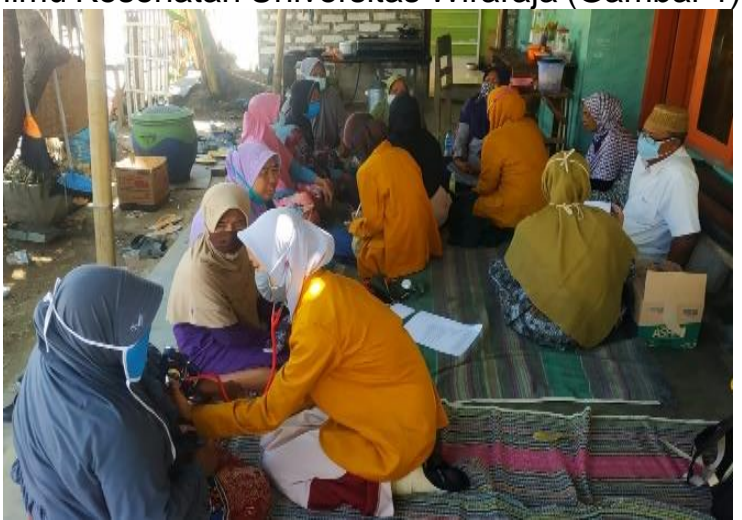

Gambar 1. Kegiatan pemeriksaan tekanan darah
2. Proses Penyampaian materi dengan metode ceramah

Tahapan kedua adalah menjelaskan materi dengan melaksanakan metode ceramah (Gambar 2) . Pada tahapan ini lansia diberikan penjelasan materi tentang hipertensi meliputi: pengertian, factor penyebab, tanda gejala, komplikasi dan cara pencegahannya.

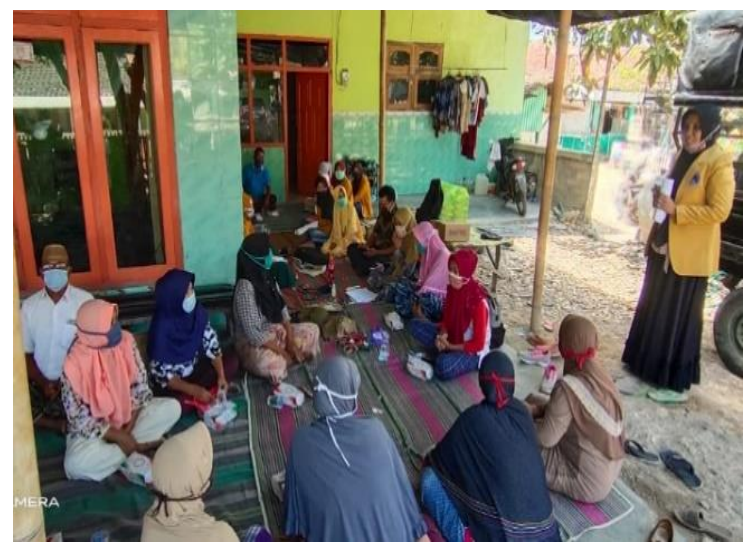

Gambar 2. Kegiatan penyampaian materi.

3. Kegiatan diskusi tanya jawab tentang materi yang tekah disampaikan

Tahapan yang ketiga yaitu pelaksanaan kegiatan diskusi (Gambar 3). Pada tahapan ini menerapkan metode diskusi ( tanya jawab). lansia berdiskusi tentang materi pendampingan yang telah dijelaskan. Bagi lansia yang urang paham maka lansia diperkenankan untuk bertanya. Selanjutnya diakhir kgiatan lansia diberikan beberapa evaluasi terkait materi yang sudah dibahas.

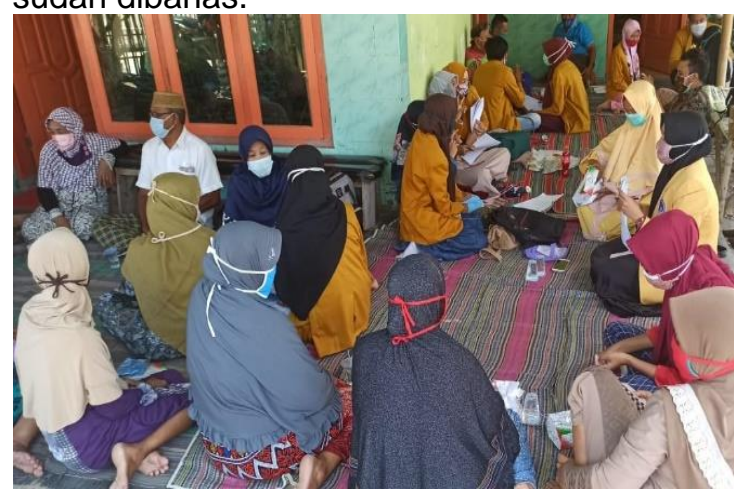

Gambar 3. Kegiatan Diskusi

Keberhasilan pendampingan pencegahan komplikasi hipertensi di rumah kader posyandu lansia bertujuan meningkatkan motivasi lansia dapat dilihat dari antusiasme dan semangat lansia yang ikut dalam pendampingan selalu bertanya terkait penyakit hipertensi. Para lansia rutin dan tepat waktu pada saat acara pendampingan. Selain itu lansia juga berperan aktif dalam melaksanakan proses berdiskusi, mereka tanpa merasa segan dalam mengajukan pertanyaan jika terdapat materi pendampingan 
yang tidak jelas dan sulit dimengerti. mereka juga aktif menjawab pertanyaan seputar materi yang telah disampaikan oleh pendamping. Kegiatan pendampingan tentang pencegahan komplikasi hipertensi ini membantu lansia dalam mengatasi ketiadaktahuannya tentang pencegahan komplikasi hipertensi. Sebagian besar lansia sudah bersikap positif terhadap pencegahan komplikasi hipertensi.

\section{SIMPULAN DAN SARAN}

Kesimpulan dalam Kegiatan pendampingan pencegahan komplikasi hipertensi di rumah kader posyandu lansia Desa karangayar barat Kecamatan kalianget Kabupaten Sumenep dapat meningkatkan pengetahuan lansia tentang hipertensi dan pencegahan komplikasinya, menumbuhkan motivasi lansia untuk mencegah komplikasi penyakit dan melaksanakan gayanhidup yang baik dalam kehidupan sehai-hari. Keberhasilan pendampingan lansia untuk menumbuhkan motivasi dalam pencegahan komplikasi penyakit hipertensi adalah dengan antusias dan semangat dalam mengikuti kegiatan pendampingan. Selain itu lansia juga aktif dalam melakukan tanya jawab dengan pendamping dan berdiskusi tentang pencegahan komplikasi hipertensi. Pelaksanaan kegiatan pengabdian ini terlaksana sesuai harapan yaitu kelancaran proses edukasi dan diskusi tanpa adanya hambatan yang cukup berarti. Sesuai dengan hal itu, perlu adanya pendampingan lansia secara berkesinambungan yang dapat dilakukan pada saat jadwal posyandu sebagai upaya membantu lansia dalam meningkatkan kualitas hidup mereka agar dapat mencegah komplikasi penyakit hipertensi.

\section{DAFTAR RUJUKAN}

Alfian, S. \&. (2015). Perbaikan Perilaku Dan Tekanan Darah Pasien Hipertensi Di Rsud Dr. H. Moch. Ansari Saleh Banjarmasin Setelah Pemberian Leaflet Edukasi Hipertensi Dan Terapinya. 1(2), 140-144.

Fernalia, F., Busjra, B., \& Jumaiyah, W. (2019). Efektivitas Metode Edukasi Audiovisual terhadap Self Management pada Pasien Hipertensi. Jurnal Keperawatan Silampari, 3(1), 221-233.

Kilic, M., Uzunçakmak, T., \& Ede, H. (2016). The effect of knowledge about hypertension on the control of high blood pressure. International Journal of the Cardiovascular Academy, 2(1), 27-32.

Mafutha, N. G., Mogotlane, S., \& de Swardt, H. C. (2017). Development of a hypertension health literacy assessment tool for use in primary healthcare clinics in South Africa,
Gauteng. African Journal of Primary Health Care and Family Medicine, 9(1), 1-9. https://doi.org/10.4102/phcfm.v9i1.1305

Nutbeam, D. (2000). Health literacy as a public health goal: A challenge for contemporary health education and communication strategies into the 21 st century. Health Promotion International, 15(3), 259-267. https://doi.org/10.1093/heapro/15.3.259

Organization, W. H. (2013). High blood Pressure: global and regional overview. World Health Day.

Suprayitno, E, \& Wahid, A. (2019). Pendampingan Tentang Penyakit Hipertensi Dan Perawatan Keluarga Dengan Hipertensi. Seminar Nasional Hasil Pengabdian ..., 104-106. http://proceeding.uim.ac.id/index.php/seni as/article/view/299

Suprayitno, E, Purnomo, J. D. T., Sutikno, S., \& Indriyani, R. (2020). Health education in principle of community affected teenagaer's smooking attitude and habitual in the coastal area of madura island indonesia. International Journal of Psychosocial Rehabilitation, 24(10), 14921502.

https://doi.org/10.37200/IJPR/V24I10/PR3 00173

Suprayitno, E. (2019). Gambaran Status Tekanan Darah Penderita Hipertensi di Desa Karanganyar Kecamatan Kalianget Kabupaten Sumenep. Journal Of Health Science (Jurnal IImu Kesehatan), 4(2), 2024. https://doi.org/10.24929/jik.v4i2.799

Taghadosi, M. (2017). The Effect of Education Based on BASNEF Model on Lifestyle in Patients with Hypertension. 19(11). https://doi.org/10.5812/ircmj.40731.Resea rch

Warjiman, Er, U. E., Yohana, G., Hapsari, \& Dwi, F. (2020). Skrining dan edukasi penderita hipertensi. Jurnal Suaka Insan Mengabdi (JSIM), 2(1), 15-26.

Widimský, J. (2016). The role of arterial hypertension in the primary prevention of stroke. Cor et Vasa, 58(2), e279-e286. 